\title{
LIVER
}

\section{Adiponectin and its receptors in non-alcoholic steatohepatitis}

\author{
S Kaser, A Moschen, A Cayon, A Kaser, J Crespo, F Pons-Romero, C F Ebenbichler, J R Patsch, \\ H Tilg
}

See end of article for authors' affiliations

....................

Correspondence to: Dr H Tilg, University Hospital Innsbruck,

Department of Medicine, Division of

Gastroenterology and

Hepatology, Anichstrasse 35,6020 Innsbruck, Austria; herbert.tilg@ vibk.ac.at

Revised version received 31 May 2004

Accepted for publication 13 June 2004
Background: Adiponectin, an adipocyte derived polypeptide, has been shown to alleviate steatosis and inflammation in mice with non-alcoholic fatty liver disease.

Aim: In the present study, we wished to define liver expression of adiponectin and its receptors in morbidly obese patients undergoing bariatric surgery. Patients with non-alcoholic steatohepatitis (NASH) or simple steatosis were investigated to test whether dysregulation of this system might be involved in these disorders. Patients and methods: Liver mRNA expression of adiponectin and its recently cloned receptors RI and RII (adipoRI and adipoRII) were analysed by fluorescence based real time polymerase chain reaction in 13 patients with NASH and nine with simple steatosis. Adiponectin and adipoRIl protein expression were assessed by immunohistochemistry in a subgroup of patients.

Results: Adiponectin and adipoRII mRNA expression were significantly reduced in liver biopsies of patients with NASH compared with simple steatosis while no difference was found in adipoRI mRNA expression. In NASH, adipoRII mRNA expression was negatively correlated with serum aspartate aminotransferase levels, serum alanine aminotransferase levels, and grade of fibrosis. Liver adiponectin protein expression was mainly found in endothelial cells of portal vessels and liver sinusoids whereas adipoRll expression was seen in hepatocytes only. Adiponectin and adipoRIl staining were lower in biopsies of subjects with NASH compared with simple steatosis.

Conclusion: Reduced hepatic expression of adiponectin and adipoRIl might be of pathophysiological relevance in non-alcoholic fatty liver diseases.
$\mathrm{N}$ on-alcoholic steatohepatitis (NASH) is frequently associated with abdominal obesity, hypertension, and diabetes. Insulin resistance has been implicated as a key mechanism in the pathogenesis of NASH. Numerous substances, mainly released by adipocytes, are thought to contribute to peripheral insulin resistance. These include proinflammatory cytokines such as interleukin (IL)-6 and tumour necrosis factor $\alpha(\mathrm{TNF}-\alpha)$ as well as leptin, resistin, and also acrp30/adiponectin/adipoQ. ${ }^{12}$ Adiponectin is an antidiabetic and antiatherogenic acting polypeptide that is strongly correlated with systemic insulin sensitivity in humans. ${ }^{134}$ Adiponectin increases fatty acid beta oxidation in muscle, ${ }^{5}$ improves postabsorptive insulin mediated suppression of hepatic glucose output by enhancing hepatic insulin action, ${ }^{6}$ and decreases lipid accumulation in macrophages. ${ }^{7}$ Beyond its metabolic effects, adiponectin also has direct anti-inflammatory effects. ${ }^{8}$

$\mathrm{Xu}$ et al reported that adiponectin administration alleviates non-alcoholic fatty liver disease in mice. In detail, administration of adiponectin improved hepatomegaly and steatosis, attenuated inflammation, and elevated levels of serum alanine aminotransferase in ob/ob mice. ${ }^{9}$

Recently, cloning of adiponectin receptors I and II (adipoRI and adipoRII) was reported. ${ }^{10}$ While in mice adipoRI is abundantly expressed in skeletal muscle, adipoRII is predominantly expressed in the liver. AdipoRI and adipoRII mediate increased AMP kinase and peroxisome proliferator activated receptor (PPAR)- $\alpha$ ligand activities, fatty acid oxidation, and glucose uptake by adiponectin, respectively.

Based on these functional characteristics of the adiponectin/adipoRI/adipoRII system, we hypothesised that dysregulation of this system could contribute to the development of $\mathrm{NASH}$ in obese subjects. We therefore determined liver expression of adiponectin and its receptors in morbidly obese patients undergoing elective bariatric surgery and compared patients with NASH with those with simple steatosis.

\section{METHODS}

\section{Study design}

Twenty two patients with a diagnosis of obesity undergoing bariatric surgery by performing a biliopancreatic diversion consisting of a partial gastrectomy with a distal Roux-en-Y reconstruction participated in this study. Subjects with a history of excessive drinking or other liver diseases, including alcoholic liver disease, viral hepatitis, autoimmune hepatitis, primary biliary cirrhosis, haemochromatosis, Wilson's disease, or $\alpha_{1}$ antitrypsin deficiency were excluded from the study. In 13 patients, NASH was defined as a clinical and pathological entity characterised by the presence of steatosis as well as lobular and/or portal inflammation with or without fibrosis ${ }^{11}$; in nine patients histologically confirmed simple steatosis was diagnosed. Liver fibrosis (scale 0-4) and steatosis (grade $0-3$ ) were assessed semiquantitatively and necroinflammatory activity was determined as described recently. ${ }^{11}$ None of the patients had signs of hepatic complications, heart failure, organic renal disease, associated autoimmune conditions, cancer, or any other severe illness. Informed written consent was obtained from all subjects.

Abbreviations: NASH, non-alcoholic steatohepatitis; adipoRI, adiponectin receptor I; adipoRII, adiponectin receptor II; AST, aspartate aminotransferase; ALT, alanine aminotransferase; $\gamma$-GT, gamma glutamyl transferase; IL, interleukin; TNF, tumour necrosis factor; GAPDH, glyceraldehyde-3-phosphate dehydrogenase; PPAR, peroxisome proliferator activated receptor; HOMA, homeostasis model assessment 


\section{Laboratory measurements}

Venous blood was drawn after an overnight fast and plasma or serum was obtained by centrifugation at $3000 \mathrm{rpm}$ for 10 minutes at $4{ }^{\circ} \mathrm{C}$ immediately after blood collection. Plasma and serum samples were either used immediately for analysis or were stored frozen at $-80^{\circ} \mathrm{C}$.

Insulin sensitivity was estimated by the homeostasis model assessment (HOMA) index. ${ }^{12}$ Aspartate aminotransferase (AST), alanine aminotransferase (ALT), gamma glutamyl transferase $(\gamma-G T)$, insulin, and glucose concentrations were measured using commercially available enzymatic kits. Serum adiponectin concentrations were determined using a commercially available radioimmunoassay kit (Linco Research Inc, St Charles, Missouri, USA).

\section{RNA isolation}

Liver biopsies were collected by Tru-cut from each subject. Total RNA was extracted from frozen liver by the acid guanidinium phenol chloroform method using Trizol reagent (Gibco, Gaithersburg, Maryland, USA). Extracted RNA was quantified by spectrophotometry. Reverse transcription of $1 \mu \mathrm{g}$ of RNA was performed using the Omniscript RT Kit (Qiagen, Hilden, Germany).

\section{Fluorescence based real time polymerase chain reaction}

mRNA of adipoRI, adipoRII, and adiponectin were estimated by quantification of adipoRI, adipoRII, adiponectin, and glyceraldehyde-3-phosphate dehydrogenase (GAPDH) cDNA by the TaqMan real time polymerase chain reaction (PCR) (Perkin Elmer, Vienna, Austria) method expressed as adipoRI/GAPDH cDNA ratio, adipoRII/GAPDH cDNA ratio, and adiponectin/GAPDH cDNA ratio, respectively.

For generation of the standard curve, serially diluted cDNA prepared from human HepG2 cells (adipoRI, adipoRII) and human SGBS cells (adiponectin) were used. Briefly, $2.5 \mu \mathrm{l}$ of each reverse transcription served as template in a $25 \mu \mathrm{l}$ PCR containing $12.5 \mu \mathrm{l}$ Taq Man Universal Polymerase Master Mix (Applied Biosystems, Foster City, California, USA), $2.25 \mu \mathrm{l}(10 \mathrm{pmol} / \mu \mathrm{l})$ of each oligonucleotide primer (MWG Ebersberg, Germany), $0.5 \mu \mathrm{l}$ of Taq Man probe ( $10 \mathrm{nmol} / \mathrm{ml}$ ) (Microsynth, Baglach, Switzerland), and $5 \mu \mathrm{l}$ aqua dest. TaqMan probes were labelled with the reporter fluorescent dye 6-carboxyfluorescein (FAM) at the $5^{\prime}$ end and with the quencher 6-carboxy-tetramethyl-rhodamine (TAMRA) at the $3^{\prime}$ end. AdipoRI, adipoRII, and adiponectin quantities were

Table 1 Anthropomorphic and clinical characteristics of all study patients

\begin{tabular}{llll}
\hline & $\begin{array}{l}\text { NASH } \\
(\mathbf{n}=13)\end{array}$ & $\begin{array}{l}\text { Controls } \\
(\mathbf{n}=9)\end{array}$ & p Value \\
\hline Age (y) & $44(3.1)$ & $34(4.3)$ & NS \\
Sex (F/M) & $9 / 4$ & $7 / 2$ & NS \\
BMI (kg/m $\left.{ }^{2}\right)$ & $45.59(1.37)$ & $47.90(2.69)$ & NS \\
AST (U/l) & $26.75(4.26)$ & $21.44(1.86)$ & NS \\
ALT (U/I) & $41.17(8.67)$ & $23.44(1.59)$ & NS \\
$\gamma$-GT (U/I) & $49.83(7.71)$ & $27.62(10.84)$ & NS \\
HOMA index & $2.32(0.61)$ & $2.34(0.87)$ & NS \\
Adiponectin ( $\mu \mathrm{g} / \mathrm{ml})$ & $5.38(0.92)$ & $6.86(1.15)$ & $\mathrm{NS}$ \\
Grade of steatosis (1-4) & $1.46(0.24)$ & $1.22(0.22)$ & $\mathrm{NS}$ \\
Grade of fibrosis (1-4) & $1.85(0.25)$ & $1.00(0)$ & $<0.01$ \\
Grade of inflammation (1-4) & $1.92(0.21)$ & $1.00(0)$ & $<0.01$ \\
\hline
\end{tabular}

$\mathrm{NASH}$, non-alcoholic steatohepatitis; BMI, body mass index; AST, aspartate aminotransferase; ALT, alanine aminotransferase; $\gamma-\mathrm{GT}$, gamma glutamyl transferase; HOMA, homeostasis model assessment. Grade of steatosis, fibrosis, and inflammation were histologically verified and classified as: grade 1, no; grade 2, light; grade 3, mild; and grade 4, severe.

Values are means (SEM). normalised to the amount of GAPDH cDNA which was determined using the GAPDH reaction mix. The PCR reaction was performed in triplicate in MicroAmp 96 well reaction plates (Perkin Elmer); amplification was carried out in the AbiPrism 7700 Sequence Detector (Perkin Elmer). Amplification conditions were two minutes at $50^{\circ} \mathrm{C}, 10 \mathrm{~min}-$ utes at $95^{\circ} \mathrm{C}$, followed by 40 cycles of 15 seconds at $95^{\circ} \mathrm{C}$, and one minute at $60^{\circ} \mathrm{C}$. Results were analysed using the Sequence Detector 1.6 software.

Oligonucleotide primers and TaqMan probes were designed using Primer express software (Perkin-Elmer Applied Biosystems, Warrington, UK). Primers included: adipoRI: forward: 5'-ACT GAG AAG AGA AAA ACA AAA ATA AAT CAT AC-3' and reverse: 5'-GAA TAA GCC AGG GTT TGG GC3'; adipoRII: forward: 5'-GCA CTA TGT CAT CTC GGA GGG3' and reverse: 5'-GCC ATC AGC ATC AAC CAG C-3'; adiponectin: forward: 5'-AGA TGG CAC CCC TGG TGA G-3' and reverse: 5'-GGG TAC TCC GGT TTC ACC G-3'; TaqMan Probes: adipoRI: 5'-TCA AAG GAT GGA GTG CAT CAA TTG GGA-3'; adipoRII: 5' -CTT AAG GCC GCC ACC ATA GGG CAG ATA-3'; and adiponectin: 5'-AAA GGA GAT CCA GGT CTT ATT GGT CCT AAG GGA-3'.

\section{Immunohistochemistry}

Immunohistochemistry for adiponectin and adipoRII was performed in liver biopsies in a subgroup of study subjects (five patients with NASH and five with simple steatosis). Polyclonal antibodies against human adiponectin and human adipoRII were purchased from R\&D Systems (McKinley Place, Minnesota, USA) and Phoenix Pharmaceuticals (Belmont, California, USA), respectively. Sections $(4 \mu \mathrm{m})$ were prepared from formalin fixed paraffin embedded tissue specimens, deparaffinised, and rehydrated in graded alcohols. A heat induced epitope retrieval technique by autoclaving slides for several minutes in $10 \mathrm{mM}$ citric acid buffer was used for detection of adiponectin and its receptors. After quenching endogenous peroxidase with $3 \% \mathrm{H}_{2} \mathrm{O}_{2}$ in phosphate buffered saline for 10 minutes, slides were incubated with primary antibodies at $4^{\circ} \mathrm{C}$ overnight (antihuman adiponectin pAb, $1 \mu \mathrm{g} / \mathrm{ml}$; antihuman adipoRII pAb, $3 \mu \mathrm{g} / \mathrm{ml}$ ). Specificity for adiponectin was demonstrated by blocking the primary antibody with recombinant human adiponectin (R\&D Systems) at $4{ }^{\circ} \mathrm{C}$ overnight. Solid phase absorbed rabbit Ig fraction (DakoCytomation, Glostrup, Denmark) was used to demonstrate specificity of adipoRII $\mathrm{pAb}$ staining. Visualisation was performed using the LSAB+ kit (DakoCytomation) with 3, 3'-diaminobenzidine as chromogen according to the manufacturer's instructions. Sections

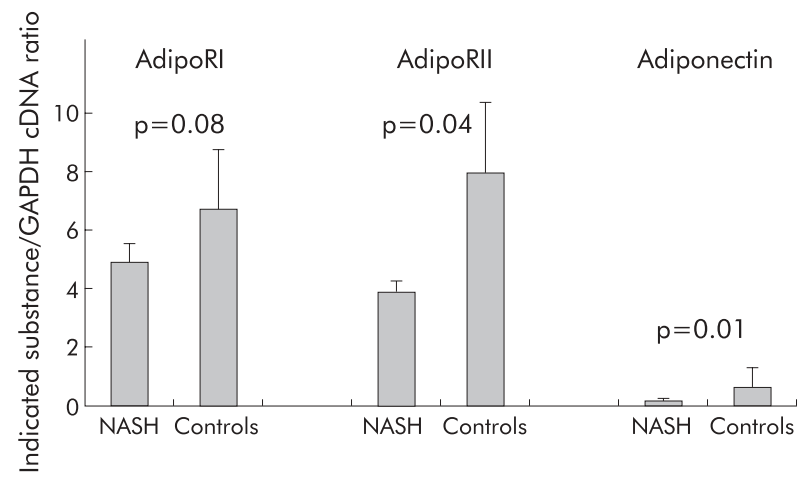

Figure 1 Adiponectin receptor I/glyceraldehyde-3-phosphate dehydrogenase (adipoRI/GAPDH) CDNA ratio, adiponectin receptor II (adipoRII)/GAPDH cDNA ratio, and adiponectin/GAPDH cDNA ratio in liver biopsies of patients with non-alcoholic steatohepatitis (NASH) and those with simple steatosis (controls). Values are means (SEM); $p$ values $<0.05$ were considered significant. 
were counterstained with haematoxylin, dehydrated, and mounted permanently in Eukitt (O Kindler GmbH, Freiburg, Germany). Finally, sections were viewed on an Olympus IX70 with Kappa camera and Kappa ImageBase 2.2 software (Kappa opto-electronics GmbH, Gleichen, Germany). Staining intensity was semiquantitatively assessed in a blinded fashion by assigning an arbitrary value of 1, 2, or 3 (reflecting weak, intermediate, and bright staining) to each specimen.

\section{Statistical analysis}

Differences between groups were calculated using the Student's $t$ test for independent samples. Statistical significance was inferred at a two tailed p value of less than 0.05 . Correlation coefficients were calculated using Pearson's method. Descriptive data are expressed as mean (SEM). SPSS for windows (version 11.0) was used for statistical analysis.

\section{RESULTS}

\section{Clinical characteristics}

Clinical characteristics of study subjects are summarised in table 1 . Body mass index, AST, ALT, $\gamma$-GT, and insulin sensitivity estimated by the HOMA index were similar in patients with NASH and simple steatosis. Serum adiponectin levels measured by radioimmunoassy were similar in patients with NASH $(5.38(0.92) \mu \mathrm{g} / \mathrm{ml})$ and those with simple steatosis (6.86 (1.15) $\mu \mathrm{g} / \mathrm{ml} ; \mathrm{p}=0.18)$.

\section{Hepatic mRNA expression}

While the adipoRI/GAPDH cDNA ratio tended to be lower in liver biopsies of subjects with NASH without reaching statistical significance (4.91 (0.62) v 6.71 (2.03); $\mathrm{p}=0.08)$, the adipoRII/GAPDH cDNA ratio was significantly decreased in liver biopsies of patients with NASH compared with those with simple steatosis (3.91 (0.35) v $7.96(2.37) ; \mathrm{p}=0.04)$. The adiponectin/GAPDH cDNA ratio was significantly lower in liver biopsies of patients with NASH $(0.15(0.07))$ compared with those with simple steatosis $(0.66(0.62) ; \mathrm{p}=0.01)$. AdipoRI/GAPDH, adipoRII/GAPDH, and adiponectin/GAPDH cDNA ratios are shown in fig 1.

Liver TNF- $\alpha$ cDNA/ $\beta$-actin cDNA ratio, as determined by semiquantitative PCR analysis, ${ }^{11}$ was significantly higher in patients with NASH compared with those with simple steatosis $(0.95 \quad(0.16) \quad v 0.22 \quad(0.08) ; \mathrm{p}<0.01)$ while liver TNF- $\alpha$ receptor type I (p55) and TNF- $\alpha$ receptor type II (p75) mRNA expression were similar in both groups.

\section{Immunohistochemistry}

Immunohistochemistry for adiponectin and adipoRII (fig 2) was performed in liver biopsies in a subgroup of our study patients (five with NASH and five with simple steatosis). Adiponectin protein expression was localised primarily to endothelial cells of portal vessels and liver sinusoids. Adiponectin staining was less pronounced in endothelial cells of liver sinusoids in patients with NASH (fig 2D, E) compared with subjects with simple steatosis (fig 2A-C) (1.4 $(0.24) v 2.25(0.25) ; p=0.05)$. AdipoRII protein was localised to hepatocytes showing a predominantly cytoplasmic staining pattern. AdipoRII staining again tended to be less pronounced in liver biopsies of subjects with NASH (fig $2 \mathrm{H}$ ) compared with subjects with simple steatosis (fig 2G) (1.6 (0.25) v $2.25(0.25) ; \mathrm{p}=0.11)$

\section{Correlations of adiponectin and its receptors with other laboratory measurements}

In subjects with NASH, adipoRII/GAPDH cDNA ratio was negatively correlated with AST $(r=-0.68, \mathrm{p}=0.02)$, ALT
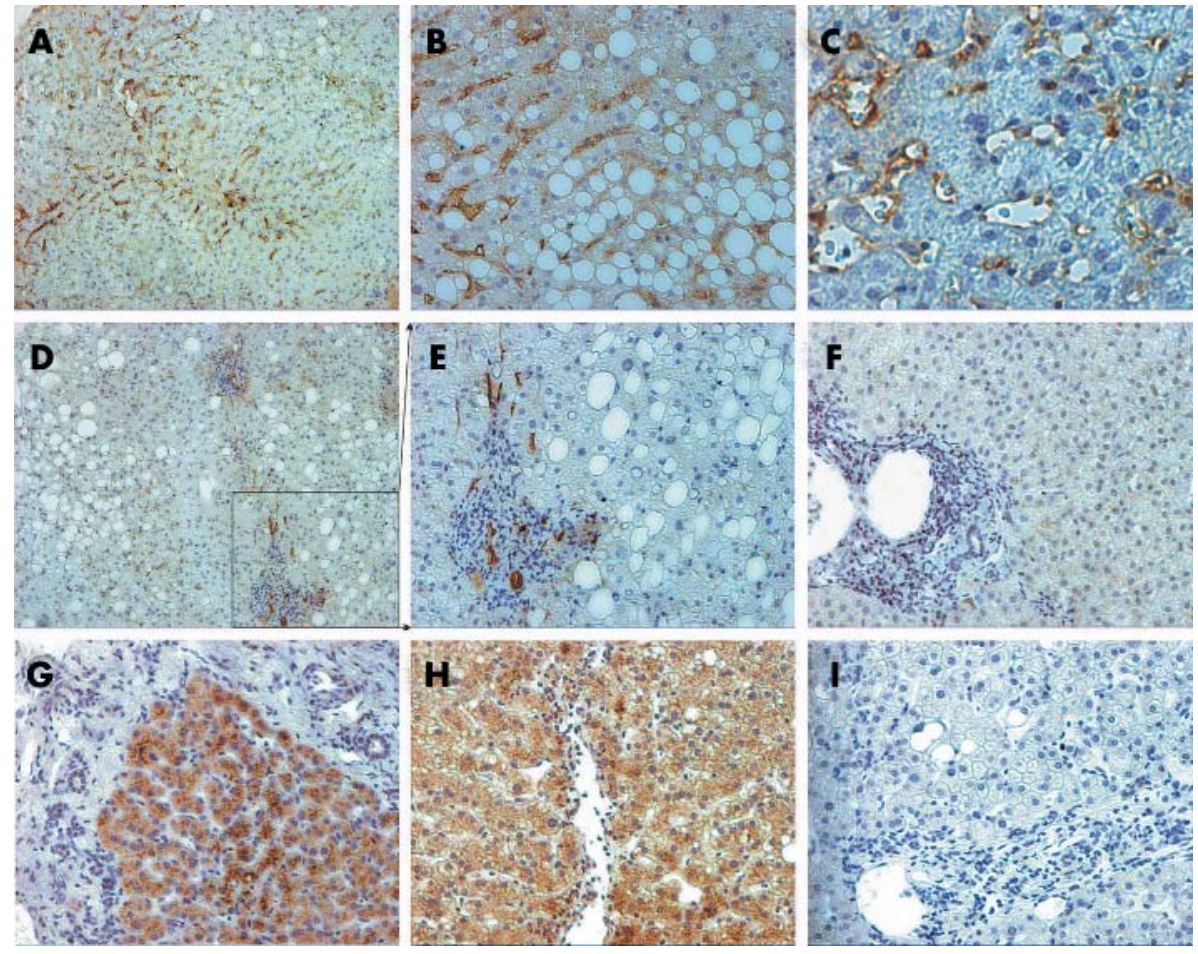

Figure 2 Immunohistochemistry for adiponectin and adiponectin receptor II (adipoRII) in human liver specimens. (A, B, C) Expression and distribution of adiponectin in simple steatosis (A 100x; B 200x; C 400x). (D, E) Staining for adiponectin in non-alcoholic steatohepatitis (NASH) (D 100x; E $200 \times$ ). Expression and distribution of adipoRll is shown in (G) (simple steatosis, $200 \times$ ) and (H) (NASH, 200 $\times$ ). Negative controls were performed by blocking adiponectin pAb with recombinant human adiponectin (F) and using a rabbit Ig fraction from non-immunised rabbits for adipoRII (I) (both $200 \times$ ). Representative experiments in liver biopsies from five patients with NASH and five with simple steatosis. 
$(r=-0.73, \mathrm{p}=0.01)$, and histological grade of fibrosis $(r=-0.58, \mathrm{p}=0.04)$. Hepatic adiponectin mRNA expression was positively correlated with grade of steatosis in patients with simple steatosis $(r=0.969, \mathrm{p}=0.03)$ while no correlation was found between these parameters in subjects with NASH. Adiponectin/GAPDH cDNA expression was significantly correlated with serum levels of $\gamma$-GT $(r=0.86$, $\mathrm{p}=0.01)$ and alkaline phosphatase $(r=0.62, \mathrm{p}=0.04)$ in subjects with NASH. No correlations were observed with these laboratory parameters in patients with simple steatosis. No correlation was found between adipoRI/GAPDH cDNA ratio and AST and ALT levels. Furthermore, there was no correlation between serum adiponectin and hepatic adiponectin, adipoRI, or adipoRII mRNA expression in any group, respectively.

When subjects with NASH and simple steatosis were analysed together, hepatic adiponectin mRNA expression was correlated with liver TNF- $\alpha$ receptor type I (p55) mRNA expression $(r=0.51, \mathrm{p}=0.05)$ while no correlation between these parameters was found when subjects with NASH or simple steatosis were considered separately. Furthermore, no correlation was identified between mRNA expression of hepatic adiponectin or its receptors and liver TNF- $\alpha /$ TNF- $\alpha$ receptor type II (p75) mRNA expression in any group.

\section{DISCUSSION}

The aim of this study was to define a potential role of adipocyte derived adiponectin and its receptors adipoRI and adipoRII in the pathogenesis of NASH in patients with severe obesity. Our results suggest that in NASH, local effects of adiponectin are limited through two different mechanisms: (i) decreased adiponectin mRNA expression and (ii) decreased mRNA expression of hepatic adipoRII. Furthermore, we observed a negative correlation between adipoRII/GAPDH cDNA ratio and AST and ALT levels and grade of fibrosis. Our immunohistochemistry data further support the notion that adiponectin and adipoRII are diminished in NASH.

In contrast with adipoRII, hepatic adipoRI mRNA expression was similar in NASH and simple steatosis. While adipoRII is predominantly expressed in the liver, ${ }^{10}$ adipoRI is mainly expressed in skeletal muscle, ${ }^{10}{ }^{13}$ suggesting that in the liver the effects of adiponectin are predominantly mediated by adipoRII. While adipoRI is a high affinity receptor for globular adiponectin, adipoRII can mediate binding of both globular and full length adiponectin and thus can increase PPAR- $\alpha$ ligand activity and fatty acid oxidation by globular and full length adiponectin. $^{10}$

Notably, adiponectin was mainly localised to endothelial cells of portal vessels and liver sinusoids while adipoRII was exclusively detected in hepatocytes. This may suggest that this hormone/receptor pair could function in a paracrine way in the liver and this interaction could be impaired in NASH. Furthermore, we found no correlation between circulating adiponectin levels and liver adiponectin expression. This could suggest that liver adiponectin expression is regulated by different factors, for example, proinflammatory cytokines such as TNF- $\alpha$.

Recently, it was reported that TNF- $\alpha$ and adiponectin suppress each other's production and are also able to antagonise each other's action. ${ }^{8}$ Therefore, reduced adiponectin mRNA expression might be partially due to these suppressive effects of elevated TNF- $\alpha$ expression in NASH. ${ }^{11}{ }^{14}$ In fact, we found increased liver TNF- $\alpha$ mRNA expression in subjects with NASH. Lack of a negative correlation between hepatic adiponectin mRNA expression and liver TNF- $\alpha$
mRNA expression might simply be due to the small number of subjects studied.

Decreased adiponectin liver activity may result in decreased fatty oxidation, glucose uptake, and reduced PPAR- $\alpha$ activity (which acts as the molecular target for lipid lowering fibrates and is strongly involved in hepatic fatty acid catabolism). Reduced effects of adiponectin on hepatic fatty acid metabolism could contribute to the development of steatohepatitis in patients with NASH. Our hypothesis is supported by the findings of $\mathrm{Xu}$ and colleagues ${ }^{9}$ who investigated the effects of adiponectin administration in $o b /$ $o b$ mice. The authors reported enhanced hepatic fatty acid oxidation and decreased acetyl-CoA carboxylase and fatty acid synthase activities-two key enzymes of fatty acid synthesis-after adiponectin delivery, resulting in reduced steatosis.

Recently, long term treatment with the PPAR- $\gamma$ agonist rosiglitazone improved not only insulin sensitivity but also ALT levels and histological markers of NASH in overweight subjects with non-alcoholic fatty liver. ${ }^{15}$ In vitro, PPAR- $\gamma$ plays a significant role in the transcriptional activation of the adiponectin gene. ${ }^{16}$ Therefore, the reported beneficial effect of rosiglitazone in patients with NASH may be due in part to the increasing effects of thiazolidinedione on adiponectin expression. $^{15} 16$

In conclusion, we have demonstrated significantly decreased adiponectin and adipoRII expression in liver biopsies of patients with NASH, suggesting that the functional pathway of this important adipokine and its liver specific receptor might be impaired in NASH.

\section{ACKNOWLEDGEMENTS}

This work was supported by grant P-15783-Med of the Austrian Science Fund (FWF) to HT and by a grant from the Spanish Ministerio de Educación y Ciencia, SAF.2001/0876 (FP).

\section{Authors' affiliations}

S Kaser, C F Ebenbichler, J R Patsch, University Hospital Innsbruck, Department of Medicine, Division of General Internal Medicine, Innsbruck, Austria

A Moschen, A Kaser, H Tilg, University Hospital Innsbruck, Department of Medicine, Division of Gastroenterology and Hepatology, Innsbruck, Austria

A Cayon, J Crespo, F Pons-Romero, University Hospital Marques de Valdecilla, School of Medicine, Institute of Digestive Diseases, Santander, Spain

Conflict of interest: None declared.

\section{REFERENCES}

1 Berg AH, Combs TP, Scherer PE. ACRP30/adiponectin: an adipokine regulating glucose and lipid metabolism. Trends Endocrinol Metab 2002;13:84-9

2 Steppan CM, Lazar MA. Resistin and obesity-associated insulin resistance. Trends Endocrinol Metab 2002;13:18-23.

3 Pellme F, Smith U, Funahashi T, et al. Circulating adiponectin levels are reduced in nonobese but insulin-resistant first-degree relatives of type 2 diabetic patients. Diabetes 2003;52:1182-6.

4 Tschritter O, Fritsche A, Thamer C, et al. Plasma adiponectin concentrations predict insulin sensitivity of both glucose and lipid metabolism. Diabetes 2003; 52:239-43.

5 Fruebis J, Tsao TS, Javorschi S, et al. Proteolytic cleavage product of 30-kDa adipocyte complement-related protein increases fatty acid oxidation in muscle and causes weight loss in mice. Proc Natl Acad Sci U S A 2001;98:2005-10.

6 Berg AH, Combs TP, Du XL, et al. The adipocyte-secreted protein Acrp30 enhances hepatic insulin action. Nat Med 2001;7:947-53.

7 Ouchi N, Kihara S, Arita Y, et al. Adipocyte-derived plasma protein, adiponectin, suppresses lipid accumulation and class $A$ scavenger receptor expression in human monocyte-derived macrophages. Circulation 2001; 103:1057-63.

8 Yokota T, Oritani K, Takahashi I, et al. Adiponectin, a new member of the family of soluble defense collagens, negatively regulates the growth of myelomonocytic progenitors and the functions of macrophages. Blood 2002;96:1723-32. 
9 Xu A Wang $Y$, Keshaw $\mathrm{H}$, et al. The fat-derived hormone adiponectin alleviates alcoholic and nonalcoholic fatty liver diseases in mice. J Clin Invest 2003;112:91-100.

10 Yamauchi T, Kamon J, Ito Y, et al. Cloning of adiponectin receptors that mediate antidiabetic metabolic effects. Nature 2003:423:762-9.

11 Crespo J, Cayon A, Fernandez-Gil P, et al. Gene expression of tumor necrosis factor alpha and TNF-receptors, p55 and p75, in nonalcoholic steatohepatitis patients. Hepatology 2001;34:1158-63.

12 Matthews DR, Hosker JP, Rudenski AS, et al. Homeostasis model assessment: insulin resistance and beta-cell function from fasting plasma glucose and insulin concentrations in man. Diabetologia 1985;28:412-19.
13 Debard $C$, Laville $M$, Berbe $V$, et al. Expression of key genes of fatty acid oxidation, including adiponectin receptors, in skeletal muscle of type 2 diabetic patients. Diabetologia 2004;47:917-25.

14 Tilg H, Diehl AM. Cytokines in alcoholic and nonalcoholic steatohepatitis. N Engl J Med 2000;343:1467-76.

15 Neuschwander-Tetri BA, Brunt EM, Wehmeier KR, et al. Improved nonalcoholic steatohepatitis after 48 weeks of treatment with the PPARgamma ligand rosiglitazone. Hepatology 2003;38:1008-17.

16 Iwaki M, Matsuda M, Maeda N, et al. Induction of adiponectin, a fat-derived antidiabetic and antiatherogenic factor, by nuclear receptors. Diabetes 2003;52:1655-63.

\section{Clinical Evidence - Call for contributors}

Clinical Evidence is a regularly updated evidence-based journal available worldwide both as a paper version and on the internet. Clinical Evidence needs to recruit a number of new contributors. Contributors are healthcare professionals or epidemiologists with experience in evidence-based medicine and the ability to write in a concise and structured way.

Areas for which we are currently seeking authors:

- Child health: nocturnal enuresis

- Eye disorders: bacterial conjunctivitis

- Male health: prostate cancer (metastatic)

- Women's health: pre-menstrual syndrome; pyelonephritis in non-pregnant women

However, we are always looking for others, so do not let this list discourage you.

Being a contributor involves:

- Selecting from a validated, screened search (performed by in-house Information Specialists) epidemiologically sound studies for inclusion.

- Documenting your decisions about which studies to include on an inclusion and exclusion form, which we keep on file.

- Writing the text to a highly structured template (about 1500-3000 words), using evidence from the final studies chosen, within 8-10 weeks of receiving the literature search.

- Working with Clinical Evidence editors to ensure that the final text meets epidemiological and style standards.

- Updating the text every six months using any new, sound evidence that becomes available. The Clinical Evidence in-house team will conduct the searches for contributors; your task is simply to filter out high quality studies and incorporate them in the existing text.

- To expand the topic to include a new question about once every 12-18 months.

If you would like to become a contributor for Clinical Evidence or require more information about what this involves please send your contact details and a copy of your CV, clearly stating the clinical area you are interested in, to Klara Brunnhuber (kbrunnhuber@ bmigroup.com).

\section{Call for peer reviewers}

Clinical Evidence also needs to recruit a number of new peer reviewers specifically with an interest in the clinical areas stated above, and also others related to general practice. Peer reviewers are healthcare professionals or epidemiologists with experience in evidence-based medicine. As a peer reviewer you would be asked for your views on the clinical relevance, validity, and accessibility of specific topics within the journal, and their usefulness to the intended audience (international generalists and healthcare professionals, possibly with limited statistical knowledge). Topics are usually 1500-3000 words in length and we would ask you to review between 2-5 topics per year. The peer review process takes place throughout the year, and our turnaround time for each review is ideally 10-14 days.

If you are interested in becoming a peer reviewer for Clinical Evidence, please complete the peer review questionnaire at www.clinicalevidence.com or contact Klara Brunnhuber (kbrunnhuber@bmigroup.com). 